\title{
Isolation and Identification of Nicotiflorin and Narcissin from the Aerial Parts of Peucedanum aucheri Boiss.
}

\author{
Zahra Ahmadian Dehaghani, Gholamreza Asghari and Masoud Sadeghi Dinani \\ Department of Pharmacognosy, Faculty of Pharmacy, Isfahan University of Medical Sciences, Isfahan 81746-73461, Iran
}

\begin{abstract}
Peucedanum aucheri Boiss. (Apiaceae) is a herbaceous wild plant native to Iran and is used in Iranian folk medicine as a diuretic and for the treatment of kidney disorders. Phytochemical investigation of different extracts prepared from the aerial part of $P$. aucheri Boiss. resulted to the isolation of two main flavonol glycosides from methanolic extract. Using comprehensive spectroscopic methods, including 1D and 2D nuclear magnetic resonance (NMR) spectroscopy and mass spectroscopy, chemical structure of isolated compounds were determined as kaempfrol-3-o-rutinoside (nicotiflorin) and isorhamnetin-3-o-rutinoside (narcissin). Although narcissin has previously been isolated from P. ruthenicum, to the best of our knowledge, isolation of nicotiflorin from Peucedanum genus is reported for the first time.
\end{abstract}

Key words: Peucedanum aucheri, Apiaceae, flavonoid, nicotiflorin, narcissin.

\section{Introduction}

The genus Peucedanum with more than 100 species in the world is one of the biggest genera in Apiaceae family, and the plants could be found in South, Western and Central Asia, Europe and mediterranean region [1]. These plants have medicinal uses and some species have been used traditionally in the treatment of cold [2], angina and as anti-tussive and anti-asthma [3]. The medicinal plant $P$. pastinacifolium Boiss. has been shown to decrease lipids in hypercholesterolemic rats [4] and posses antispasmodic activity on rat's ileum [5], while the antimicrobial activity of $P$. ruthenicum $\mathrm{M}$. Bieb was shown against gram-positive and gram-negative bacteria [6]. A variety of other medicinal effects, such as antiplatelet aggregation [7], antioxidant [8], antimycobacterial [9] and antimutagenic activity [10], have also been demonstrated for different plants of this genus in other studies.

Coumarins, flavonoids, butenolides, chromones, terpenes and sterols are the main natural compounds that have been isolated from different Peucedanum species through the last phytochemical studies [11].

Corresponding author: Masoud Sadeghi Dinani, assistant professor, research field: pharmacognosy.
Among them, flavonoids are more investigated and interested compounds, and many flavonoids have been isolated from different species of this genus. Isolation of quercetin, rutin, isorhamnetin, kaempferol and quercetin-3-o-rutinoside from different species of Pecudanum are the most important examples [11, 12].

Flavonoids are of pharmacological importance, and their antiatherosclerotic, anti-inflammatory, antitumor, antithrombogenic, anti-angiogenesis, antiviral, antibacterial and antifungal effects have been demonstrated through numerous scientific studies [13]. Inverse correlation between flavonoid intake and total plasma cholesterol concentration [14], inverse correlation of flavonoids intake and incidence of dementia [15] and decreasing the risk of death from coronary heart disease in elderly patients [16] are other important medicinal benefits of flavonoid intake in humans.

$P$. aucheri Boiss., which is called in Kurdish "Ba-reh-za", is a herbaceous wild plant native to Iran [17] and considerably used as a condiment in the west provinces of Iran, especially in Kurdistan and Kermanshah. P. aucheri is also a medicinal plant, and in Iranian folk medicine, it has been generally used as 
a diuretic and for the treatment of kidney disorders. This study aimed to investigate the chemical structure of main flavonoids existing in the aerial parts of $P$. aucheri Boiss..

\section{Materials and Methods}

\subsection{Plant Material}

Aerial parts of $P$. aucheri Boiss. were collected in May 2014 from Marivan city, Kurdistan province, Iran. The plant was characterized by Mrs Farahnaz Houshidari, botanical expert of Research Center for Agriculture and Natural Resources in Kurdistan and a voucher specimen (No. 3487) has been registered and kept in Department of Pharmacognosy, Faculty of Pharmacy, Isfahan University of Medical Science, Isfahan, Iran.

\subsection{General Methods}

$\mathrm{H}$ nuclear magnetic resonance (HNMR) and $\mathrm{C}$ nuclear magnetic resonance (CNMR) spectra were recorded by Bruker $400 \mathrm{MHz}(\mathrm{H}$ at $400 \mathrm{MHz}$ and $\mathrm{C}$ at $100 \mathrm{MHz}$ ) spectrometer, using $\mathrm{CD}_{3} \mathrm{OD}$ as solvent and also for signal calibration $\left(\delta_{H}=3.31, \delta_{C}=49.0\right)$. One-bond heteronuclear ${ }^{1} \mathrm{H}-{ }^{13} \mathrm{C}$ connectivities were determined with $2 \mathrm{D}$ heteronuclear single-quantum coherence (HSQC) pulse sequence with an interpulse delay set for ${ }^{1} \mathrm{~J}_{\mathrm{CH}}$ of $130 \mathrm{~Hz}$, while two and three bond heteronuclear ${ }^{1} \mathrm{H}-{ }^{13} \mathrm{C}$ connectivities, determined with 2D heteronuclear multiple bond correlation (HMBC), were optimized for ${ }^{2-3} J_{\mathrm{CH}}$ of $8 \mathrm{~Hz}$.

Medium pressure liquid chromatography (MPLC) was performed by Buchi Gradient System C-605 apparatus using glass columns of LiChroprep ${ }^{\circledR}$ RP- 18 (25-40 $\mu \mathrm{m})$ and C-660 Buchi fraction collector. Thin layer chromatography (TLC) was done when necessary on silicagel $60 \quad \mathrm{~F} 254$ plates using BuOH: $\mathrm{H}_{2} \mathrm{O}: \mathrm{CH}_{3} \mathrm{CO}_{2} \mathrm{H}$ 60:25:15 (BAW) as mobile phase and cerium sulfate in $2 \mathrm{~N} \mathrm{H}_{2} \mathrm{SO}_{4}$ and natural product (NP) as reagents for visualizing the spots.

High-performance liquid chromatography (HPLC) was performed by Waters 515 apparatus equipped with a refractive index detector (Waters 2414) and semipreparative C18 column (Novapak $^{\circledR} 3.9 \mathrm{~mm} \times$ $300 \mathrm{~mm}$ ), in isocratic mode.

\subsection{Extraction, Isolation and Identification}

Air-dried powdered aerial parts of $P$. aucheri Boiss. $(1.1 \mathrm{~kg})$ were extracted at room temperature in a three step extraction method with the following solvents at increasing polarity: hexane, dichloromethane (DCM) and methanol (MeOH). Each step was conducted for 1 day under stirring and repeated three times using $5 \mathrm{~L}$ of solvent. All the extracts were concentrated to dryness using rotary evaporator and checked with TLC $\left(\mathrm{SiO}_{2}, \mathrm{BAW}\right.$ 60:15:25, v/v/v) for interesting phenolic compounds.

The methanol extract $(78 \mathrm{~g})$ was subjected to column chromatography by MPLC instrument on a glass column $(36 \mathrm{~mm} \times 460 \mathrm{~mm})$, filled by silicagel (40-63 $\mu \mathrm{m}$ ) using a linear gradient of MeOH:DCM with increasing polarity. Analyzing the eluates by TLC $\left(\mathrm{SiO}_{2}, \mathrm{BAW} 60: 15: 25, \mathrm{v} / \mathrm{v} / \mathrm{v}\right)$, the 10th fraction was subjected to reverse column chromatography on a RP-18 glass column $\left(36 \mathrm{~mm} \times 460 \mathrm{~mm}\right.$, Lichroprep ${ }^{\circledR}$, $25-40 \mu \mathrm{m}$ ) using a linear gradient solvent system of $\mathrm{H}_{2} \mathrm{O}$ to $\mathrm{MeOH}$. Based on TLC $\left(\mathrm{SiO}_{2}\right.$, BAW 60:15:25, $\mathrm{v} / \mathrm{v} / \mathrm{v}$ ) and preliminary NMR analysis of the eluates, two fractions were considered to be rich on phenolic compounds and selected for final purification by HPLC.

The first fraction was subjected to purification by HPLC using a semi preparative C18 column and $\mathrm{H}_{2} \mathrm{O}-\mathrm{MeOH}$ (50:50) isocratic mobile phase, resulting the compound $1\left(5 \mathrm{mg}, t_{R}=11 \mathrm{~min}\right)$ as a pure flavonoid glycoside.

The second fraction was first re-fractionated by MPLC instrument on a RP-18 column $(15 \mathrm{~mm} \times 460$ $\mathrm{mm})$ with a linear gradient of $\mathrm{MeOH}: \mathrm{H}_{2} \mathrm{O}(15: 85)$ to pure $\mathrm{MeOH}$. An aliquot of the main sub-fraction was then subjected to purification by recrystallization, which finally yielded the compound $2(7 \mathrm{mg})$ as a pure flavonoid glycoside. 


\section{Results and Discussion}

Two flavonol glycosides were isolated and purified from the methanolic extract of the aerial parts of $P$. aucheri.

Compound 1 was isolated as a yellowish powder. High resolution analysis of compound 1 on the molecular ion peak in the negative ion mode gave a peak at $\mathrm{m} / \mathrm{z}=593.25 \mathrm{M}-\mathrm{H}$, indicating the molecular formula as $\mathrm{C}_{27} \mathrm{H}_{30} \mathrm{O}_{15}$. CNMR spectrum in agreement with the molecular formula showed 27 carbon signals, while, HNMR spectrum of compound 1 revealed the characteristic signals of flavonol glycosides. Two singlet proton signals at $\delta_{\mathrm{H}} 6.23(\mathrm{~s}, 1 \mathrm{H}, \mathrm{H}-6)$ and $\delta_{\mathrm{H}}$ 6.43 (s, $1 \mathrm{H}, \mathrm{H}-8)$, followed by two doublet proton signals at $\delta_{\mathrm{H}} 6.91\left(\mathrm{~d}, J=8.9 \mathrm{~Hz}, 2 \mathrm{H}, \mathrm{H}-3^{\prime}\right.$ and $\left.\mathrm{H}-5^{\prime}\right)$ and $\delta_{\mathrm{H}} 8.09\left(\mathrm{~d}, J=8.9 \mathrm{~Hz}, 2 \mathrm{H}, \mathrm{H}-2^{\prime}\right.$ and H-6') revealed the kaempferol-like nature of the aglycon part of the compound (Table 1). There were also two anomeric proton signals at $\delta_{\mathrm{H}} 5.15(\mathrm{~d}, J=7.5 \mathrm{~Hz}, 1 \mathrm{H}$, Glu-1) and $\delta_{\mathrm{H}} 4.54$ (bs, $1 \mathrm{H}$, Rha-1), which together with overlapped proton signals at $\delta_{\mathrm{H}} 3-4$, demonstrating the glycosilated nature of compound 1 as

Table $1 \quad{ }^{1} \mathrm{H}$ and ${ }^{13} \mathrm{C}$ NMR data of flavonol glycosides isolated from the aerial parts of $P$. aucheri.

\begin{tabular}{|c|c|c|c|c|}
\hline \multirow[t]{2}{*}{ Position } & \multicolumn{2}{|c|}{$\begin{array}{c}\text { Compound 1 } \\
\text { (kaempferol- 3-O-rutinoside) }\end{array}$} & \multicolumn{2}{|c|}{$\begin{array}{c}\text { Compound } 2 \\
\text { (isorhamnetin-3-o-rutinoside) }\end{array}$} \\
\hline & $\delta_{\mathrm{H}}($ mult., int., $J(\mathrm{~Hz}))$ & $\delta_{\mathrm{C}}$ & $\delta_{\mathrm{H}}($ mult., int., J (Hz)) & $\delta_{\mathrm{C}}$ \\
\hline 2 & - & 158.30 & - & 157.80 \\
\hline 3 & - & 134.50 & - & 134.65 \\
\hline 4 & - & 178.80 & - & 178.50 \\
\hline 5 & - & 161.70 & - & 162.40 \\
\hline 6 & $6.23(\mathrm{~s}, 1 \mathrm{H})$ & 99.98 & $6.12(\mathrm{~s}, 1 \mathrm{H})$ & 99.95 \\
\hline 7 & - & 165.80 & - & 165.32 \\
\hline 8 & $6.43(\mathrm{~s}, 1 \mathrm{H})$ & 94.95 & $6.31(\mathrm{~s}, 1 \mathrm{H})$ & 94.86 \\
\hline 9 & - & 158.30 & - & 158.40 \\
\hline 10 & - & 104.80 & - & 104.94 \\
\hline $1^{\prime}$ & - & 122.60 & - & 123.16 \\
\hline $2^{\prime}$ & $8.08(\mathrm{~d}, 1 \mathrm{H}, 8.9 \mathrm{~Hz})$ & 132.40 & $7.55(\mathrm{~s}, 1 \mathrm{H})$ & 115.71 \\
\hline $3^{\prime}$ & $6.90(\mathrm{~d}, 1 \mathrm{H}, 8.9 \mathrm{~Hz})$ & 116.09 & - & 148.92 \\
\hline $4^{\prime}$ & - & 160.40 & - & 149.81 \\
\hline $5^{\prime}$ & $6.92(\mathrm{~d}, 1 \mathrm{H}, 8.9 \mathrm{~Hz})$ & 116.09 & $6.78(\mathrm{~d}, 1 \mathrm{H}, 8.0 \mathrm{~Hz})$ & 116.06 \\
\hline $6^{\prime}$ & $8.10(\mathrm{~d}, 1 \mathrm{H}, 8.9 \mathrm{~Hz})$ & 132.40 & $7.57(\mathrm{~d}, 1 \mathrm{H}, 8.0 \mathrm{~Hz})$ & 123.55 \\
\hline $3^{\prime}-\mathrm{OCH}_{3}$ & - & - & $3.25(\mathrm{~s}, 1 \mathrm{H})$ & 55.02 \\
\hline $1^{\prime \prime}$ & $5.15(\mathrm{~d}, 1 \mathrm{H}, 7.5 \mathrm{~Hz})$ & 104.61 & $5.16(\mathrm{~d}, 1 \mathrm{H}, 7.5 \mathrm{~Hz})$ & 104.70 \\
\hline $2^{\prime \prime}$ & $3.21-3.85^{\mathrm{a}}$ & 75.77 & $3.21-3.72^{\mathrm{a}}$ & 75.72 \\
\hline $3^{\prime \prime}$ & $3.21-3.85^{\mathrm{a}}$ & 78.14 & $3.21-3.72^{\mathrm{a}}$ & 77.19 \\
\hline $4^{\prime \prime}$ & $3.21-3.85^{\mathrm{a}}$ & 71.44 & $3.21-3.72^{\mathrm{a}}$ & 71.39 \\
\hline $5^{\prime \prime}$ & $3.21-3.85^{\mathrm{a}}$ & 77.21 & $3.21-3.72^{\mathrm{a}}$ & 78.17 \\
\hline $6^{\prime \prime}$ & $3.21-3.85^{\mathrm{a}}$ & 68.56 & $3.21-3.72^{\mathrm{a}}$ & 68.54 \\
\hline $1^{\prime \prime \prime}$ & $4.54(\mathrm{bs}, 1 \mathrm{H})$ & 102.21 & $4.42(\mathrm{bs}, 1 \mathrm{H})$ & 102.43 \\
\hline $2^{\prime \prime \prime}$ & $3.21-3.85^{\mathrm{a}}$ & 72.10 & $3.21-3.72^{\mathrm{a}}$ & 72.11 \\
\hline $3^{\prime \prime \prime}$ & $3.21-3.85^{\mathrm{a}}$ & 72.29 & $3.21-3.72^{\mathrm{a}}$ & 72.22 \\
\hline $4^{\prime \prime \prime}$ & $3.21-3.85^{\mathrm{a}}$ & 73.89 & $3.21-3.72^{\mathrm{a}}$ & 73.92 \\
\hline $5^{\prime \prime \prime}$ & $3.21-3.85^{\mathrm{a}}$ & 69.75 & $3.21-3.72^{\mathrm{a}}$ & 69.72 \\
\hline $6^{\prime \prime \prime}$ & $1.14(\mathrm{~d}, 1 \mathrm{H}, 6.0 \mathrm{~Hz})$ & 17.94 & $1.02(\mathrm{~d}, 1 \mathrm{H}, 6.0 \mathrm{~Hz})$ & 17.90 \\
\hline
\end{tabular}

Mult.: multiplicity of the NMR signal; int: integral of the NMR signal (showing the number of H); $J$ : coupling constant ( $J$ coupling); s: singlet; bs: broad singlet; d: doublet; ${ }^{a}$ overlapped with other signals. 


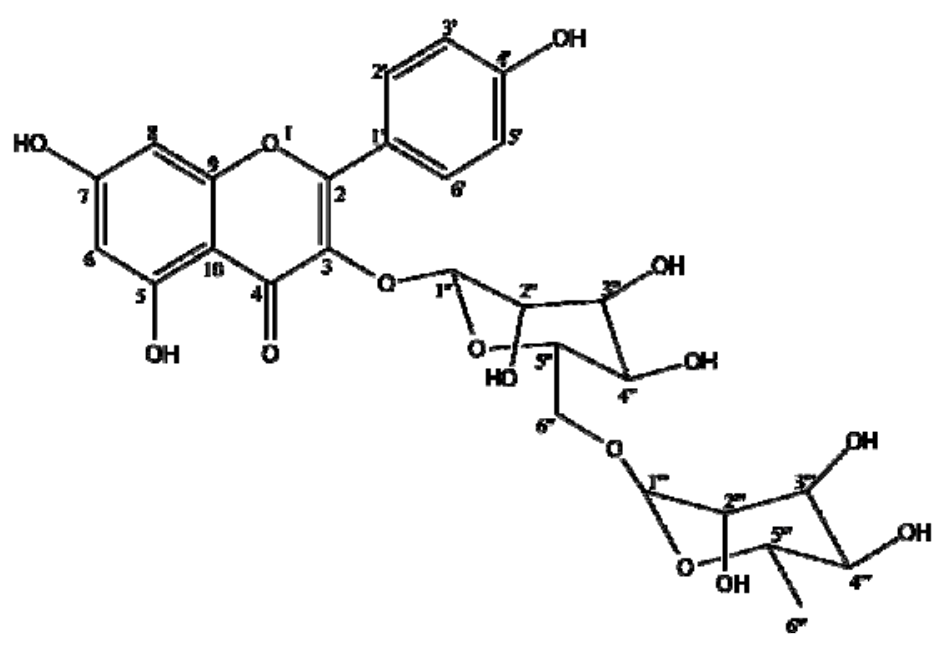

Fig. 1 Chemical structure of compound 1 (kaempferol 3-O-rutinoside) isolated from the aerial parts of P. aucheri.

a rutinoside unit. Observing a big singlet at $\delta_{\mathrm{H}} 1.14(\mathrm{~d}$, $1 \mathrm{H}, J=6 \mathrm{~Hz}$, Rha-CH3), typical of rhamnose methoxyl group, was also used to confirm the presence of rhamnose in the chemical structure of compound 1. According to these data and by comparing them with the NMR data of different flavonol glycosides reported in the literature [18], the structure of compound 1 was defined as kaempferol 3-O-rutinoside (nicotiflorin) (Fig. 1).

Compound 2 was also isolated as a yellowish powder. Comparing the NMR spectrum of this compound with that of compound 1 exhibited a great amount of similarity between the two compounds, except for the presence of a 3'-methoxyl group in the compound 2. Two doublet proton signals at $\delta_{\mathrm{H}} 6.12(\mathrm{~d}$, $1 \mathrm{H}, \mathrm{H}-6, J=2.5 \mathrm{~Hz})$ and $\delta_{\mathrm{H}} 6.31(\mathrm{~d}, 1 \mathrm{H}, \mathrm{H}-8, J=2.5$ $\mathrm{Hz}$ ), together with a doublet proton signal at $\delta_{\mathrm{H}} 6.78$ (d, $\left.J=8.0 \mathrm{~Hz}, 1 \mathrm{H}, \mathrm{H}-5^{\prime}\right)$ and an overlapped proton signal at about $\delta_{\mathrm{H}} 7.57\left(\mathrm{~d}, J=8.0,1 \mathrm{H}, \mathrm{H}-6{ }^{\prime}\right.$ and s, $1 \mathrm{H}$, H-2') were observed in the HNMR spectra of compound 2, revealing the substituted-flavonol nature of the aglycon part of compound 2. A big singlet of methoxyl group existed at HNMR spectrum $\left(\delta_{\mathrm{H}} 3.25\right.$; s, $3 \mathrm{H}, 3$ ' $-\mathrm{OCH}_{3}$ ), which was supported by the methoxyl carbon signal at CNMR spectrum $\left(\delta_{\mathrm{C}} 55.02\right)$, confirming the presence of a methoxyl group in the chemical structure of aglycon part of compound 2 (Table 1). According to these data and the NMR data reported in Ref. [1], the chemical structure of compound 2 was defined as isorhamnetin 3-O-rutinoside (narcissin) (Fig. 2).

Many secondary metabolites, including flavonoids and coumarins, have been isolated from various parts of many Peucedanum species [11]. In this study, two O-glycosilated flavonol derivatives, namely nicotiflorin and narcissin, were isolated from the aerial parts of $P$. aucheri, an important edible and medicinal plant, common to the west regions of Iran.

Nicotiflorin is a naturally occurred flavonol glycoside, which has been isolated from plant species, like Astragalus armatus [19], Edgeworthia chrysantha [20], Caragana bungei [21], Flos sophorae immaturus [22], Carthamus tinctorius [23] and Acalypha hispida [24]. It has been demonstrated to have many interesting pharmacological activities, such as decreasing arterial blood pressure and heart rate [25], hepatoprotective effects on $\mathrm{CCl}_{4}$-induced liver injury [23], potent antioxidant, anti-inflammatory, antinociceptive [26], antihypertensive and antianaphylactic effects [27] and had a protective effect against cerebral ischemic damage [28]. It is also known that nicotiflorin have a protective effect against memory dysfunction and oxidative stress in multi-infarct dementia model rats [29].

Narcissin is also a natural flavonol glycoside and has been isolated from plant species, like P. ruthenicum [1], 


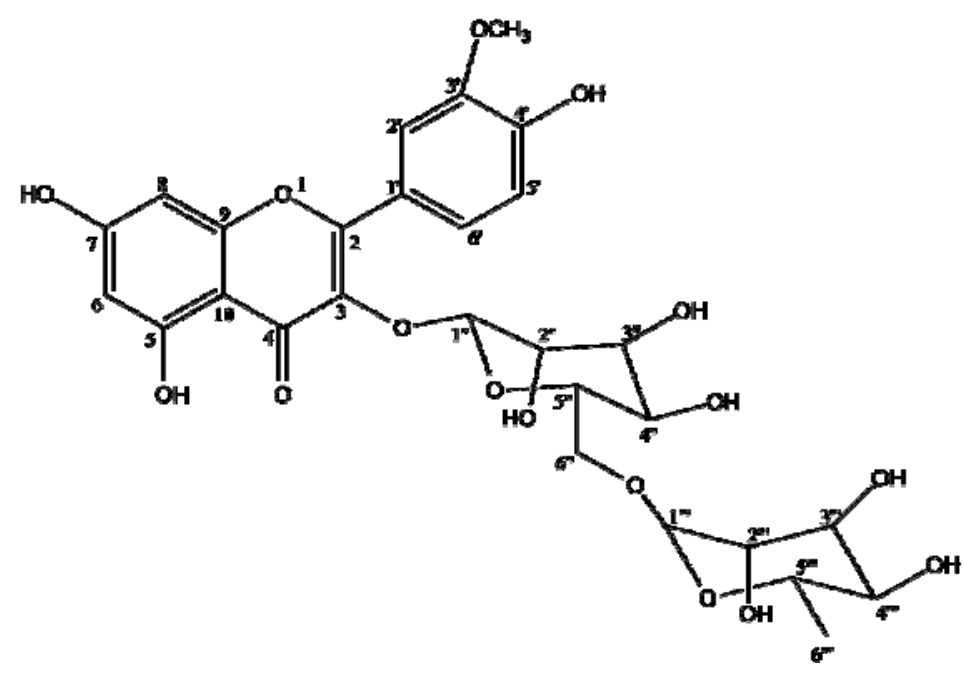

Fig. 2 Chemical structure of compound 2 (isorhamnetin-3-O-rutinoside) isolated from the aerial parts of $P$. aucheri.

Caragana bungei [21], Avicennia marina [30], Calotropis gigantean [31] and Aristolochia kankauensis [32]. It has been proved to have important medicinal activities, including induction of apoptosis in human myelogenous erythroleukaemia cells [33], markedly increasing the coronary flow and decreasing the arterial blood pressure, the oxygen consumption and the myocardial contractile force (MCF) in isolated hearts [34], antiprotozoal activity that showing selectivity against Entamoeba histolytica [35] and anthelmintic effect against gastrointestinal nematodes [36].

\section{Conclusions}

Phytochemical investigation of Peucedanum aucheri Boiss. showed the isolation of nicotiflorin and narcissin as the main phenolic constituents from aerial parts of the plant. Although narcissin has been previously isolated from $P$. ruthenicum, isolation of nicotiflorin from Peucedanum species is reported for the first time by this study and could be used to investigate and explain the medicinal properties of the plant.

\section{Acknowledgments}

The authors are grateful to Isfahan University of Medical Sciences for financial supporting of the project.

\section{References}

[1] Alavi, S. H. R., Yasa, N., Hajiaghaee, R., Yekta, M. M., Rezaei, N., Ajani, Y., and Hadjiakhondi, A. 2009. "Phenolic Compounds from Peucedanum ruthenicum M. Bieb." Iranian J. Pharm. Res. 8 (1): 71-5.

[2] Gan, W. S. 1965. Manual of Medicinal Plants in Taiwan. Vol. 3. Taipei, Taiwan: Notional Research Institute of Chinese Medicine, 675.

[3] Tang, W., and Einsehbrand, G. 1992. Chinese Drugs of Plant Origin: Chemistry, Pharmacology and Use in Traditional and Modern Medicine. Berlin, Heidelberg: Springer-Verlag, 753-7.

[4] Movahedian, A., Sajjadi, S. E., and Ahmadi, M. 2009. "Lipid Lowering Effect of Ethanolic Extract of Aerial Parts of Peucedanum pastinacifolium Boiss. and Hausskn. in Hypercholesterolemic Rats." Iranian J. Pharm. Res. 8 (4): 301-6.

[5] Sadraei, H., Asghari, G. R., and Motaqedi, M. 2015, "Evaluation of Anti-spasmodic Effect of Peucedanum pastinacifolium Extracts on Rat's Ileum.” Res. Pharm. Sci. 10 (6): 497-503.

[6] Sabri, N., Yassa, N., Fazeli, M. R., Alavi, S. H. R., Fouladi, F., Salimi, L., Manayi, A., and Tofighi, Z. 2009. "Antibacterial Activity of Peucedanum ruthenicum, Johreniopsis seseloides and Cervaria cervariifolia Extracts." Iranian J. Pharm. Sic. 5 (1): 37-42.

[7] Chen, I. S., Changa, C. T., Sheena, W. S., Teng, C. M., Tsaia, I. L., Duh, C. Y., and Ko, F. N. 1996. "Coumarins and Antiplatelet Aggregation Constituents from Formosan Peucedanum japonicum." Phytochemistry 41 (2): 525-30. 
[8] Hisamoto, M., Kikuzaki, H., Ohigashi, H., and Nakatani, N. 2003. "Antioxidant Compounds from the Leaves of Peucedanum japonicum Thumb.." J. Agric. Food Chem. 51 (18): 5255-61.

[9] Schinkovitz, A., Gibbon, S., Staviri, M., Cocksedge, M. J., and Bucar, F. 2003. "Ostruthin: An Antimycobicterial Coumarin from the Roots of Peucedanum ostruthium." Planta Med. 69 (4): 369-71.

[10] Miyazawa, M., Shimamura, H., Bhuva, R., and Kameoka, H. 1996. "Antimutagenic Activity of Falcarindiol from Peucedanum praeroptorum." J. Agric. Food Chem. 44 (11): 3444-8.

[11] Kuzmanov, B., Andreev, N., and Kozovska, V. 1981. "Chemotaxonomic Study on Bulgarian Species of Peucedanum L.." Anales Jardin Botanico de Madrid 37 (2): 779-88.

[12] Alavi, S. H. R., Yasa, N., Fouladi, F., and Shafiee, A. 2006. "Chemical Composition of the Essential Oils of Peucedanum ruthenicum M. Bieb. Leaves, Flowers and Fruits." Iranian J. Pharm. Res. 5 (2): 143-7.

[13] Agrawal, A. D. 2011. "Pharmacological Activities of Flavonoids: A Review." Inter. J. Pharm. Sci. and Nanotech. 4 (2): 1394-8.

[14] Arai, Y., Watanaabe, S., Kimira, M., Shimoi, K., Mochizuki, R., and Kinae, N. 2000. "Dietary Intakes of Flavonols, Flavones and Isoflavones by Japanese Women and the Inverse Correlation between Quercetin Intake and Plasma LDL Cholesterol Concentration.” J. Nutr. 130 (9): 2243-50.

[15] Commenges, D., Scotet, V., Renaud, S., Jacqmin-Gadda, H., Barberger-Gateau, P., and Dartiques, J. F. 2000, "Intake of Flavonoids and Risk of Dementia." Eur. J. Epidemiol. 16 (4): 357-63.

[16] Hertog, M. G., Kromhout, D., Aravanis, C., Blackburn, H., Buzina, R., Fidanza, F., Giampaoli, S., Jansen, A., Menotti, A., and Nedeljkovic, S. 1995. "Flavonoid Intake and Long-Term Risk of Coronary Heart Disease and Cancer in the Seven Countries Study." Arch. Intern. Med. 155 (4): 381-6.

[17] Mozaffarian, V. A. 1996. Dictionary of Iranian Plant Names. Tehran: Farhang Moaser, 402.

[18] Rejon, G. E., Rodriguez, P., and Sterner, O. 2010. "Isolation of Kaempferol-3-Rutinoside from the Leaf Extract of Sideroxylon foetidissimum subsp. gaumeri." Rev. Latinoam Quim. 38 (1): 7-10.

[19] Khalfallah, A., Karioti, A., Berrehal, D., Kabouche, A., Lucci, M., Bilia, A. R., and Kabouche, Z. 2014. "A New Triglycoside and Other Flavonol Glycosides from Astragalus armatus Willd. (Fabaceae)." Rec. Nat. Prod. 8 (1): $12-8$.

[20] Tong, S. H., Yan, J., Chen, G., and Lou, J. 2009. "Purification of Rutin and Nicotiflorin from the Flowers of Edgeworthia chrysantha Lindl. by High-Speed Countercurrent Chromatography." J. Chromatogr. Sci. 47 (5): 341-4.

[21] Olennikov, D., Tankhaeva, L., Partikhaev, V., and Rokhin, A. 2012. "Chemical Constituents of Caragana bungei Shoots." Brazil J. Pharma. 22 (3): 490-6.

[22] Xie, Z. S., Sun, Y. J., Lam, S. C., Zhao, M. Q., Liang, Z. K., Yang, D., Yu, X. X., and Xu, X. J. 2014. "Extraction and Isolation of Flavonoid Glycosides from Flos Sophorae Immaturus Using Ultrasonic-Assisted Extraction Followed by High-Speed Countercurrent Chromatography.” J. Separa. Sci. 37 (8): 957-65.

[23] Wang, Y., Tang, C. Y., and Zhang, H. 2015. "Hepatoprotective Effects of Kaempferol 3-O-Rutinoside and Kaempferol 3-O-Glucoside from Carthamus tinctorius L. on CCl4-Induced Oxidative Liver Injury in Mice.” J. Food Drug Anal. 23 (2): 310-7.

[24] Adesina, S. K., Idowu, O., Ogundaini, A. O., Oladimeji, H., Olugbade, T. A., Onawunmi, G. O., and Pais, M. 2000. "Antimicrobial Constituents of the Leaves of Acalypha wilkesiana and Acalypha hispida." Phytother. Res. 14 (5): 371-4.

[25] Ahmad, M., Hassan Gilani, A., Aftab, K. H., and Ahmad, V. U. 1993. "Effects of Kaempfrol 3-O-Rutinoside on Rat Blood Pressure." Phytother. Res. 7 (4): 314-6.

[26] Gamal-Eldeen, A. M., Kawashty, S. A., Ibrahim, L. F., Shabana, M. M., and El-Negoumy, S. I. 2004. "Evaluation of Antioxidant, Antiinflammatory and Antinociceptive Properties of Aerial Parts of Vicia sativa and Its Flavonoids." J. Nat. Remed. 4 (1): 81-96.

[27] Ishiguro, K., Ohira, Y., and Oku, H. 2002. "Preventive Effects of Impatiens balsamina on the Hen Egg-White Lysozyme (HEL)-Induced Decrease in Blood Flow." Biol. Pharm. Bull. 25 (4): 505-8.

[28] Li, R., Guob, M., Zhang, G., Xua, X., and Li, Q. 2006. "Nicotiflorin Reduces Cerebral Ischemic Damage and Upregulates Endothelial Nitric Oxide Synthase in Primarily Cultured Rat Cerebral Blood Vessel Endothelial Cells.” J. Ethnopharmacol. 107 (1): 143-50.

[29] Huang, J. L., Fu, S. T., Jiang, Y. Y., Cao, Y. B., Guo, M. L., Wang, Y., and Xu, Z. 2007. "Protective Effects of Nicotiflorin on Reducing Memory Dysfunction, Energy Metabolism Failure and Oxidative Stress in Multi-infarct Dementia Model Rats." Pharmacol. Biochem. Behav. 86 (4): 741-8.

[30] Sharaf, M., EI-Ansari, M. A., and Saleh, N. A. 2000. "New Flavonoids from Avicennia marina." Fitoterapia 71 (3): 274-7.

[31] Sen, S., Sahu, N. P., and Mahato, S. B. 1992. "Flavonol Glycosides from Calotropis gigantea." Phytochemistry 31 (8): 2919-21.

[32] Wu, T. S., Ou, L. F., and Teng, C. M. 1994. “Aristolochic 

Aerial Parts of Peucedanum aucheri Boiss.

Acids, Aristolactam Alkaloids and Amides from Aristolochia kankauensis." Phytochemistry 36 (4): 1063-8.

[33] Boubaker, J., Bhouri, W., Ben Sghaier, M., Ghedira, K., Dijoux-Franca, M. G., and Chekir-Ghedira, L. 2011. "Ethyl Acetate Extract and Its Major Constituent, Isorhamnetin 3-O-Rutinoside, from Nitraria retusa Leaves, Promote Apoptosis of Human Myelogenous Erythroleukaemia Cells." Cell Prolif. 44 (5): 453-61.

[34] Chen, L. F., Wang, G. X., Li, Q. A., and Liu, G. H. 1987. "Comparison of Effects of Narcissin and Ligustrazin on
Cardiac Hemodynamics." Zhonqquo Yao Li Xue Bao 8 (2): 123-7. (in Chinese)

[35] Calzada, F., Velazquez, C., Cedillo-Rivera, R., and Esquivel, B. 2003. "Antiprotozoal Activity of the Constituents of Teloxys graveolens." Phytother. Res. 17 (7): 731-2.

[36] Barrau, E., Fabre, N., Fouraste, I., and Hoste, H. 2005. "Effect of Bioactive Compounds from Sainfoin (Onobrychis viciifolia Scop.) on the in Vitro Larval Migration of Haemonchus contortus: Role of Tannins and Flavonol Glycosides." Parasitology 131 (4): 531-8. 